Archived version from NCDOCKS Institutional Repository http://libres.uncg.edu/ir/asu/

Cherry, T. L., Cotton, S. J., \& Jones, L. R. (2013). The appropriation of endogenously provided common-pool resources. Resource and Energy Economics, 35(3), 329-341. Publisher's version available from www.elsevier.com (ISSN: 0928-7655). DOI: 10.1016/j.reseneeco.2013.03.001

\title{
The appropriation of endogenously provided common-pool resources
}

Todd L. Cherry, Stephen J. Cotton, Luke R. Joseph

\begin{abstract}
Because game theory suggests that the origin of a common-pool resource should not affect appropriation behavior, experimental studies of appropriation from common-pool resources generally presume resources are exogenously provided. However, behavioral economic research indicates that the origin of a resource may affect the use of that resource. We investigate the potential role of resource origin by considering the appropriation of a common-pool resource after users have determined its productive capacity through contributions. Results indicate that resource origin does not significantly influence aggregate appropriation levels but that endogenous resource provision leads to individual strategic behavior.
\end{abstract}

\section{Keywords}

Common-pool resource; Experiment; Reciprocity 


\section{Introduction}

Social dilemmas have been a principal source of inquiry in the behavioral sciences for over half a century. In 1950, Merrill Flood and Melvin Dresher, scientists at the RAND Corporation, introduced a two-person social dilemma that was soon to be known as the prisoner's dilemma. A few years later, Paul Samuelson provided an initial characterization of the public good dilemma, an n-person social dilemma in which each individual may pay a cost that generates a benefit shared by all ( Samuelson, 1954). The commons dilemma was popularized soon afterwards by Garrett Hardin's "Tragedy of the Commons," when he described an n-person social dilemma in which each individual may receive a benefit that imposes a cost shared by all ( Hardin, 1968). These seminal efforts set in motion an abundance of research that has produced a vast literature on social dilemmas.

The fascination is warranted because, by presenting situations in which private and collective interest conflict, social dilemmas offer a powerful setting to explore fundamental questions of self-interest, cooperation, social norms and reciprocity within the broader purpose of improving social well-being. Indeed, considerable effort has been expended to better understand how behavioral and institutional elements can facilitate cooperative solutions and collective action (e.g., Baland and Platteau, 1996, Bischoff, 2007, Ostrom, 2000, Ostrom, 2006 and Varughese, 1999). As a result, research has moved beyond the notion that cooperative behavior is always thwarted by individual self-interest and can only be realized by externally imposed institutions of private property or government intervention (Fehr and Gächter, 2000 and Ostrom, 2000). It is well-documented that people often exhibit cooperative behavior when conventional theory predicts otherwise, whether it is cooperating on the provision of public goods or the management of shared resources (e.g., Isaac and Walker, $\underline{1998}$ and Lam, 1998).

Much of our understanding of social dilemmas comes from the extensive experimental work on public goods and common-pool resources (CPRs). Since early experiments by Walker et al. (1990) confirmed theoretical predictions of overexploitation of CPRs, a vast literature has employed the same basic experimental framework to examine the institutional factors and behavioral levers that affect appropriation of CPRs. These papers address an array of issues such as resource uncertainty (e.g., Budescu et al., 1995); collective choice and voting (e.g., Walker et al., 2000); externalities of spatially linked resources (Schnier, 2009); and communication (e.g., Ostrom, 2006). Surprisingly, the body of experimental work on CPRs almost exclusively relies on exogenously provided resources despite the fact not all resources are "manna from heaven." CPRs are often endogenously determined by collective actions to improve and maintain the resource before choices are made on how to appropriate it (Ostrom et al., 1994). 
Members of user groups act collectively to develop and maintain irrigation systems that harness common water resources (Ostrom, 1996) and to cultivate common land for collective harvests (West, 2010). In fact, policies in many countries have explicitly shifted the provision of common resources to local user groups, as illustrated by the Ugandan government transferring the responsibility of de-silting the Doho Irrigation Rice Canals to local users (Meinzen-Dick et al., 2002 and Sserunkuuma et al., 2008).

We consider the case of such endogenously determined CPRs. More specifically, we examine whether appropriation of a CPR depends on whether its potential benefits are exogenously provided or endogenously determined. While theory suggests the origin of the CPR should not affect appropriation behavior, the literature provides considerable evidence that the origin of resources affects how people use those resources (Thaler, $\underline{1985}$ and Arkes et al., 1995). ${ }^{1}$ In game-theoretic settings, the literature reports that individuals exhibit less cooperation and more self-interest when they must exert effort to secure resources (e.g. Cherry et al., 2002, Harrison, 2007 and Janssen et al., 2011). Research also indicates that the process of cooperating in a task may lead to greater cooperation in a different subsequent task (Vyrastekova and van Soest, 2003). Prior research therefore provides a basis to suspect appropriation behavior is influenced by the CPR being endogenously determined by a collective action rather than exogenously provided. Considering the prevalence of endogenously determined resources in the field and the reliance on exogenously provided resources in the lab, it is worth testing the theoretical presumption that resource origin does not affect appropriation.

Endogenous provision also presents a unique opportunity to see if people identify and exploit opportunities for strategic reciprocity in order to motivate cooperation. For instance, members of the collective may punish free-riding in provision by overappropriating the resource. Alternatively, members may opt to signal cooperation or reward cooperative behavior by under-appropriating. Previous experimental studies on negative and positive reciprocity in social dilemmas indicate that cooperative behavior can be promoted when members of a collective have the option to punish other members for non-cooperative behavior (e.g., Fehr and Gächter, 2000 and RodriguezSickert et al., 2008) or reward them for cooperative behavior (e.g., Andreoni et al., $\underline{2003}$ and Sefton et al., 2007). Janssen et al. (2011), a rare exception in the CPR literature in that it examines both provision and appropriation, explores an analogue of the dictator game where downstream users of an irrigation system are dependent upon the appropriation decisions of upstream users. Though the authors' experiment does not compare exogenously and endogenously determined resources, their findings do provide some indirect evidence of negative reciprocity in the provision and appropriation decisions of users. Our experimental design, which includes both exogenous and 
endogenous provision, allows us to determine the effect of resource origin on both individual strategic behavior and aggregate appropriation levels.

\section{Framework}

We extend the standard CPR game used by Walker et al. (1990) that has served as the framework for numerous CPR experiments. In the Walker et al. experiments, a group of $n$ users plays a non-cooperative game in which each user makes an appropriation decision; users allocate an endowment between a CPR with exogenous productive capability and a private alternative. We extend this basic framework to consider endogenously determined productive capability by allowing each user to contribute some of her endowment toward increasing the return of the CPR. Users make provision and appropriation decisions in two separate stages and observe the outcome of provision before deciding on appropriation.

\subsection{Stage 1: provision}

At the beginning of each period, user $i$ is endowed with $e$ to be allocated between contributions, $C$ i, toward enhancing the return of the CPR and for use in the subsequent appropriation stage. If aggregate contributions meet a threshold, $T$, the stock of the CPR is increased and users experience a higher rate of return on any given level of appropriation in the appropriation stage. Let the stock of the resource, $S\left(\Sigma_{i=1}^{n} c_{i}\right)$ $\mathrm{S}(\Sigma \mathrm{i}=1 \mathrm{nci})$, take the value $S_{0}$ if contributions fall below the threshold $\left(\sum_{i=1}^{n} c_{i}<T\right)$ $(\Sigma \mathrm{i}=1 \mathrm{nci}<\mathrm{T})$ and value $S_{T}>S_{0}$ if contributions meet or exceed the threshold $\left(\sum_{i=1}^{n} c_{i} \geq T\right)\left(\sum \mathrm{i}=1 \mathrm{nci} \geq \mathrm{T}\right)$.

The threshold, $T$, and size of the enhancement, $S_{T}-S_{0}$, are known to users. Aggregate contributions less than $T$ are wasted, as are the portion of contributions in excess of $T$, so there are only two potential Nash equilibrium outcomes: $\sum_{i=1}^{n} c_{i}=0$ $\sum \mathrm{i}=1 \mathrm{nci}=0$ and $\sum_{i=1}^{n} c_{i}=T \sum \mathrm{i}=1 \mathrm{nci}=\mathrm{T}$.

\subsection{Stage 2: appropriation}

Users simultaneously allocate their remaining endowments between appropriation, $a$, from the CPR and investment, $e-c_{i}-a_{i}$, in a private alternative. The aggregate return, $R$, from the CPR is a function of aggregate appropriation, $A=\sum_{i=1}^{n} a_{i}$ $A=\Sigma i=1$ nai, and the resource stock, $S$, where $b$ is an exogenous functional parameter:

$$
R(A, S)=S A-b A^{2}
$$

The individual return on appropriation, $r_{i}$, is equal to an individual's share of total appropriation multiplied by the aggregate return: 
The private alternative yields a constant rate of return to investment, $w$, so that an individual's return from investment in the private alternative is given by $\left(e-c_{i}-a_{i}\right) w$. Individual $i$ 's second stage problem, taking the appropriation decisions of the other users as given, is to maximize individual payoff, $\pi_{i}$, over $a_{i}$ :

$$
\max _{a_{i}} \pi_{i}=w\left(e-c_{i}-a_{i}\right)+\left(\frac{a_{i}}{A}\right)\left[S A-b A^{2}\right]
$$

The unconstrained Nash equilibrium level of individual appropriation is given by:

$$
a^{N E}=\frac{S-w}{b(n+1)}
$$

Users anticipate Nash behavior in the appropriation stage of the game when making their decisions in the provision stage. Substituting (4) into the individual payoff in (3) and taking the difference in individual payoff when the resource is enhanced vs. unenhanced yields:

(5)

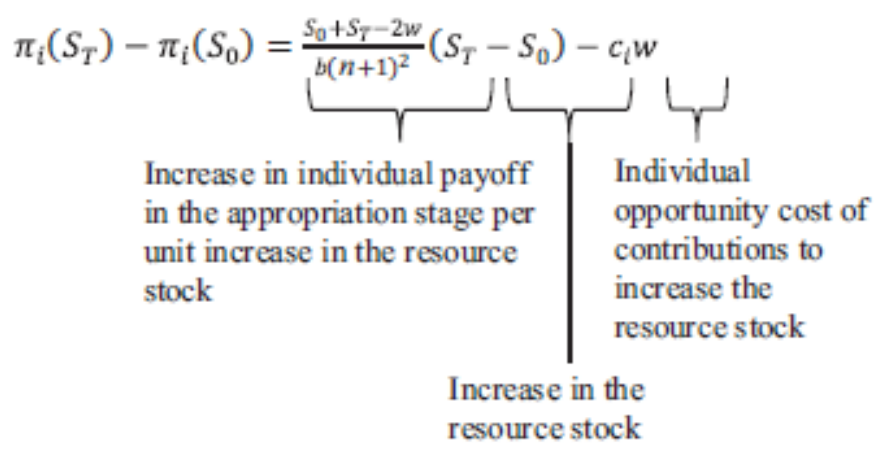

Recall that the only potential equilibrium outcomes for contributions are zero or the threshold $\left({ }_{i=1}^{n} c_{i}=0 \sum \mathrm{i}=1 \mathrm{nci}=0\right.$ or $\left.\sum_{i=1}^{n} c_{i}=T \sum \mathrm{i}=1 \mathrm{nci}=\mathrm{T}\right)$. Intuitively, if the increase in payoff from the appropriation stage is less than the cost of enhancement (i.e., if Eq. (5) is negative) for a symmetric contribution, $T / n$, neither it nor any asymmetric contribution profile that achieves the threshold can be an equilibrium. In this case, the Nash equilibrium for provision is that each individual contributes nothing $\left(c{ }_{i}=0, \forall i\right)$. On the other hand, if (5) is positive for $c_{i}=T$, each player has an incentive to unilaterally enhance the resource by contributing $T$ if no other player contributes, so all contribution combinations that result in $\sum_{i=1}^{n} c_{i}=T \sum \mathrm{i}=1 \mathrm{nci}=\mathrm{T}$ are Nash equilibria. Finally, for the intermediate case where (5) is positive for $c_{i}=T$ In but negative for 
$c_{i}=T$, contributions leading to either $\sum_{i=1}^{n} c_{i}=0 \sum \mathrm{i}=1 \mathrm{nci}=0$ or $\sum_{i=1}^{n} c_{i}=T_{\sum \mathrm{i}=1 \mathrm{nci}=\mathrm{T}}$ are Nash equilibria. ${ }^{3}$ Moving forward, we focus on this intermediate and most interesting case where symmetric enhancement is beneficial for individuals playing strategies consistent with the Nash equilibrium concept but not so great as to make unilateral enhancement worthwhile.

To conclude our discussion of the experimental framework we turn our attention to the provision mechanism through which resource enhancement is achieved. In this paper, we consider two mechanisms that are well-documented in the literature: a voting mechanism and a provision point mechanism (PPM).

\subsection{Voting mechanism}

With the voting mechanism, each user is able to vote for or against (i.e., "yes" or "no") a mandate for each group member to contribute an equal share to enhance the CPR. If a majority votes "yes," then $c_{i}=T / n$, the resource is enhanced, and each user has her remaining endowment to allocate in the appropriation stage. If a majority votes "no," then $c_{i}=0$, the resource remains unenhanced, and

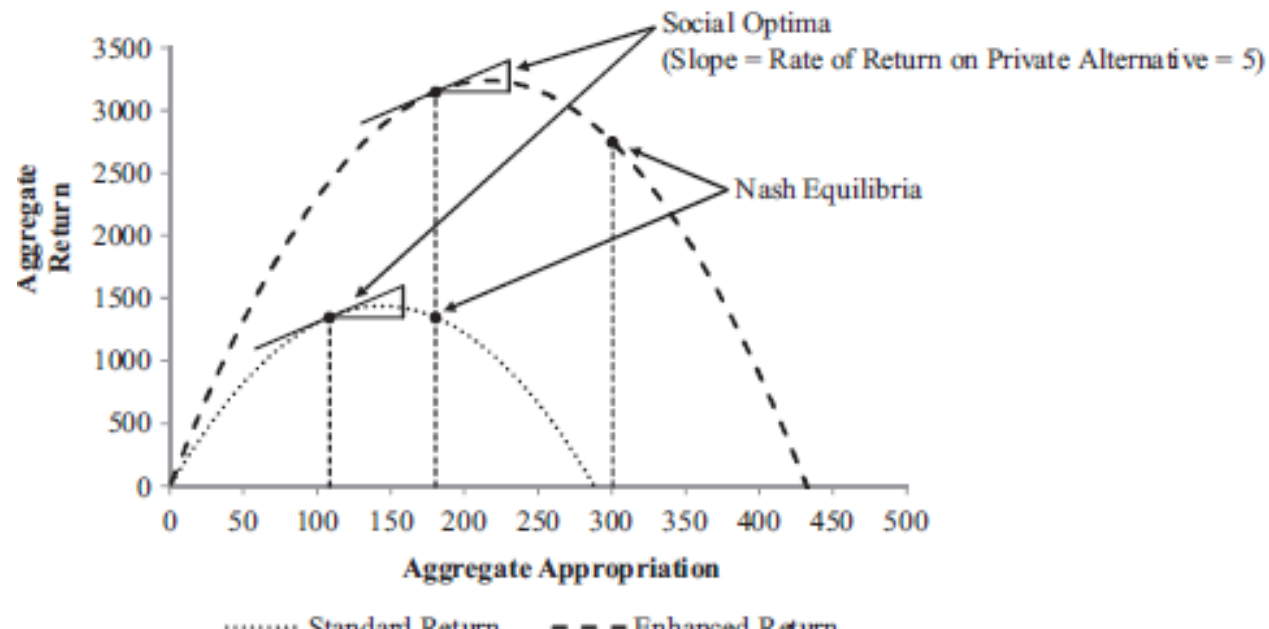

Fig. 1. Enhancement of the resource

each user keeps her full endowment. Because users are better off through enhancement and pay no cost if the vote fails, voting "yes" is a weakly dominant strategy (if the voter was decisive, strictly dominant). Eliminating weakly dominated strategies yields a single symmetric equilibrium where each voter votes "yes," and we would expect to observe provision and appropriation by each user of $\left(c_{i}=T / n\right.$, $\left.a_{i}=S_{T}-w / b(n+1)\right)$. 


\subsection{Provision point mechanism}

The other type of provision mechanism we test is a provision point mechanism (PPM) (see Bagnoli and McKee, 1991 for discussion on PPM experiments). With the PPM, each user has the opportunity to make a voluntary contribution toward CPR enhancement. If $\sum_{i=1}^{n} c_{i} \geq T \sum \mathrm{i}=1 \mathrm{nci} \geq \mathrm{T}$, the resource is enhanced, otherwise the CPR remains unenhanced. Because aggregate contributions below or above the threshold are wasted, we implement a PPM with no refund or rebate (Cadsby and Maynes, 1999), i.e., any contributions that individuals make are spent regardless of the provision outcome. For this implementation of the PPM there are two symmetric equilibria $\left(c_{i}=0\right.$ and $\left.c_{i}=T / n\right)$, and a multitude of asymmetric equilibria that all result in the threshold

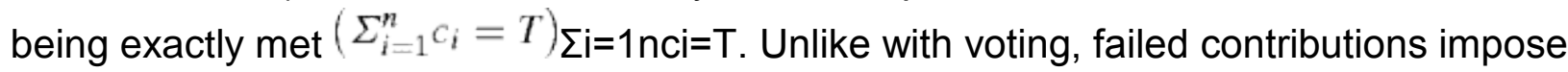
a cost and there is a free-riding incentive, so there is no weakly dominant strategy to contribute. Therefore with the PPM we would expect to observe average provision and appropriation by each user of either $\left(c_{i}=T / n, a_{i}=S_{T}-w / b(n+1)\right)$ or $\left(c_{i}=0\right.$, $\left.a_{i}=S_{0}-w / b(n+1)\right)$.

\section{Experimental design}

We parameterize the theory to develop explicit predictions, defining the following: $n=5$, $w=5, b=5 / 72, T=100, S_{0}=20, S_{T}=30$, and $e=120$. Fig. $1^{4}$ shows the aggregate return functions for standard and enhanced states of the resource given these parameters. Comparing the standard and enhanced returns for Nash equilibrium appropriation, it is clear that enhancing the resource is a desirable outcome for users: an equal share of the threshold would cost each individual 20 in contributions (an opportunity cost of 100 foregone from investment in the private account) and would yield anticipated individual gains of 160 in the appropriation stage. However, it is not worthwhile for an individual to unilaterally pay the opportunity cost of enhancement (500). In the voting mechanism, voting "yes" is a weakly dominant strategy for all players, so we expect the vote to pass. In the PPM, there is a symmetric Nash equilibrium in which the resource is enhanced, with each user contributing 20 , but there

Table 1. Experimental design.

\begin{tabular}{|c|c|c|c|c|c|}
\hline Treatment & $\begin{array}{l}\text { Provision } \\
\text { outcome }\end{array}$ & $\begin{array}{l}\text { Initial } \\
\text { endowment }\end{array}$ & $\begin{array}{l}\text { Individual } \\
\text { contribution }\end{array}$ & $\begin{array}{l}\text { Remaining } \\
\text { endowment }\end{array}$ & $\begin{array}{l}\text { CPR type } \\
\text { appropriated }\end{array}$ \\
\hline Baseline: enhanced & $\mathrm{n} / \mathrm{a}$ & 100 & $\mathrm{n} / \mathrm{a}$ & 100 & Enhanced \\
\hline Baseline: standard & $\mathrm{n} / \mathrm{a}$ & 120 & $\mathrm{n} / \mathrm{a}$ & 120 & Standard \\
\hline \multirow[t]{2}{*}{ Voting mechanism (Vote) } & Passes & 120 & 20 & 100 & Enhanced \\
\hline & Fails & 120 & 0 & 120 & Standard \\
\hline \multirow{2}{*}{ Provision point mechanism (PPM) } & Met & 120 & 20 & 100 & Enhanced \\
\hline & Not Met & 120 & 0 & 120 & Standard \\
\hline
\end{tabular}

Note: Individual contribution is restricted to 0 and 20 in the Vote treatment, depending on the outcome of the referenda. Contributions are not restricted in the PPM treatment; we report 0 and 20 as the two symmetric Nash contribution levels. 
is also a free-riding Nash equilibrium in which each user contributes zero, and the resource remains unenhanced. Due to the presence of possible free-riding, we suspect that enhancement will occur less frequently in the PPM than in the voting mechanism.

Regardless of the mechanism used for providing the resource, the standard gametheoretic approach yields Nash equilibrium appropriation that, conditional on the stock of the resource, does not depend on the way the resource is determined. Therefore, the Nash prediction of appropriation is 36 per user if the resource is unenhanced and 60 per user if the resource is enhanced, independent of whether the resource is determined exogenously, or endogenously through voting or a PPM. Nonetheless, previous work suggests the origin of the resource might influence appropriative behavior. The experiment is designed to examine this possibility.

Table 1 summarizes the experimental design, which consists of two baseline treatments and two provision treatments. The two baseline treatments, enhanced baseline and standard baseline, follow the typical CPR experimental framework in that subjects only play the appropriation stage (no provision stage). The rate of return from the CPR is exogenously provided and is based on $S_{0}$ in the standard baseline ${ }^{5}$ and $S_{T}$ in the enhanced baseline. In the provision treatments, subjects participate in a provision stage before the appropriation stage and endogenously determine the rate of return from the resource through voting in the Vote treatment, and through a provision point mechanism in the PPM treatment.

We conducted six sessions-one for each of the baseline treatments, and two sessions for each of the provision treatments. We used a "between-subjects" design in which each subject only participated in one treatment. Each session contained three groups in a partner design and lasted for 20 periods. The partner design opens channels for reciprocal behavior and is consistent with previous CPR experiments and observations in the field where CPRs are used over an extended period of time by the same population.

All sessions were conducted in an experimental economics laboratory at a large public university, with a total of 90 participants recruited from the undergraduate student population. The experiment was computerized using Fischbacher (2007)'s z-Tree, and a moderator explained all instructions (available from authors upon request) to the students as they followed along on their individual workstations. All relevant information about the game was clearly explained to subjects. A short exercise tested knowledge, and subjects could not proceed until all questions were answered correctly. 
Returns from the resource were communicated to subjects using tables containing aggregate returns. Subjects in the standard baseline were provided tables with the standard aggregate returns, while subjects in the enhanced baseline were provided tables with the enhanced aggregate returns. Subjects in the provision treatments were provided tables with both the standard and enhanced aggregate returns. If the vote passed in the voting treatment, or if the threshold was at least met in the PPM treatment, then subjects used the enhanced table, otherwise subjects used the standard table.

Table 2. Summary of group provision by treatment.

\begin{tabular}{|c|c|c|c|c|}
\hline \multicolumn{3}{|c|}{ Vote } & \multicolumn{2}{|l|}{ PPM } \\
\hline & All periods & Last 5 periods & All periods & Last 5 periods \\
\hline $\begin{array}{l}\text { Mean Group } \\
\text { Contributions }\end{array}$ & $\begin{array}{l}93.3 \\
(2.01)\end{array}$ & $\begin{array}{l}100,0 \\
(0,0)\end{array}$ & $\begin{array}{l}97.4 \\
(5.18)\end{array}$ & $\begin{array}{l}93.5 \\
(7.86)\end{array}$ \\
\hline $\begin{array}{l}\text { Success Rate of } \\
\text { Enhancement }(\%)\end{array}$ & $\begin{array}{l}93.3 \\
(2.01)\end{array}$ & $\begin{array}{l}100,0 \\
(0,0)\end{array}$ & $\begin{array}{l}63.3 \\
(11,12)\end{array}$ & $\begin{array}{l}70,0 \\
(15.37)\end{array}$ \\
\hline
\end{tabular}

Notes: Conditional group means are reported with clustered (on groups) robust standard errors in parentheses; in the last fiv periods, all groups in the vote treatment successfully enhanced the resource.

Experimental earnings were denominated in tokens and were converted into \$US at a rate of $\$ 0.001$ per token at the end of the session. Subjects could conceivably lose money in a period (none did) or earn as much as $\$ 2.60$. Game-theoretic play with enhanced provision in every period would yield $\$ 20.00$ for the session including a $\$ 5$ show-up fee, which is very close to the payment average of $\$ 19.24 .^{-}$Sessions took slightly less than an hour on average.

\section{Results}

We organize the results by first looking separately at the outcomes of the provision and appropriation stages, and then exploring potential linkages between them.

\subsection{Provision stage}

Table 2 presents the details on the group contributions and outcomes in the provision stage of the game. Mean group contributions are similar across the treatments $(p=0.46$ ${ }^{7}$ ), registering 93.3 in the Vote treatment and 97.4 in the PPM treatment. This finding persists through the final five periods. Indeed, Fig. 2 illustrates relatively consistent contributions over time, which corresponds to previous work on voting and provision point mechanisms ( Walker et al., 2000 and Croson and Marks, 2000).

Differences emerge when we consider the rate of resource enhancement. In the Vote treatment, the resource is enhanced in 93.3 percent of cases, while enhancement occurs in only 63.3 percent of cases in the PPM treatment $(p=0.02)$. This difference in 
resource enhancement remains even when we only consider the final five periods. Thus, while the voting and PPM mechanisms generate similar contributions, the voting mechanism is more effective in translating the contributions into successful resource enhancement. This finding is consistent with previous findings that a binding vote mechanism is effective at coordinating collective action ( Walker et al., 2000 and Kroll et al., 2007).

\subsection{Appropriation stage}

Table 3 reports the conditional means of group appropriation for each treatment. Joint tests reveal that appropriation levels are statistically equivalent across treatments conditional on the stock of the resource (standard: $p=0.56$; enhanced: $p=0.34$ ). Comparing appropriation levels to game-theoretic predictions, we find that the Nash solution concept organizes the data well. Appropriation levels are statistically equivalent to the game-theoretic predictions in four of the six cases, with differences

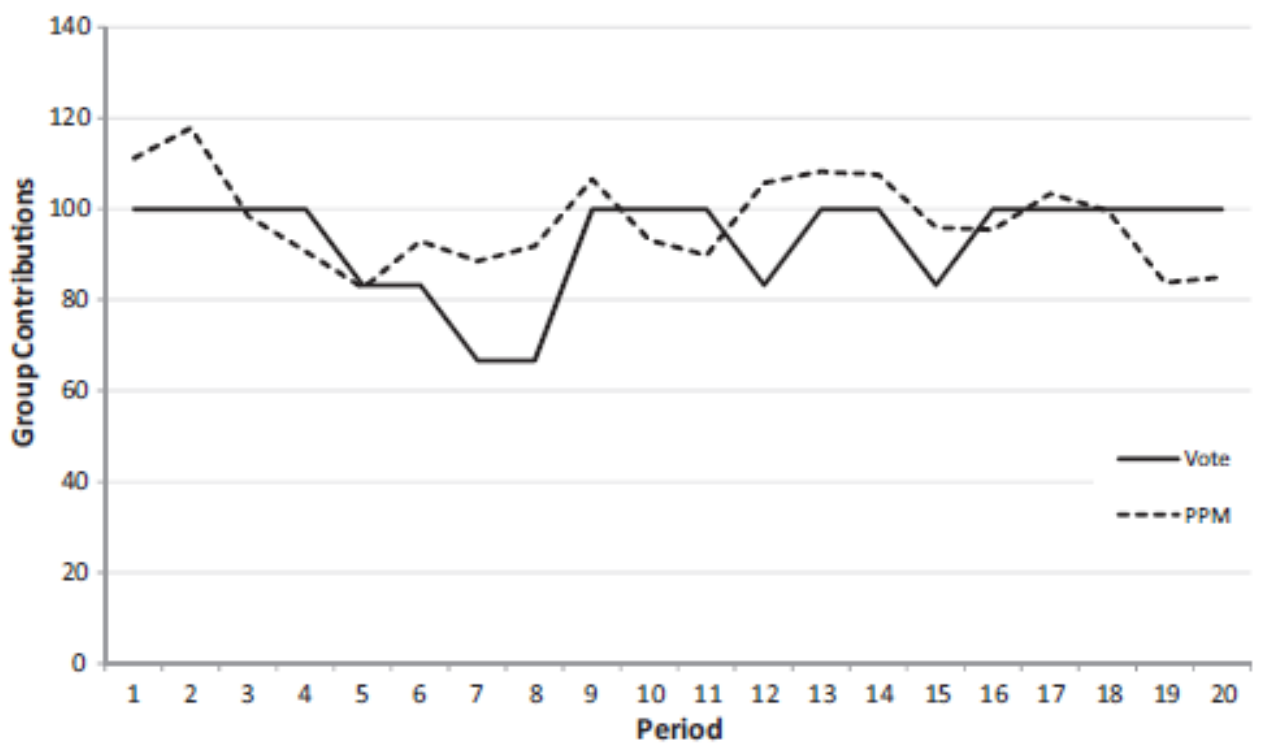

Fig. 2. Mean group provision

Table 3. Mean group appropriation by treatment and provision decision.

\begin{tabular}{|c|c|c|c|c|}
\hline \multirow[t]{2}{*}{ 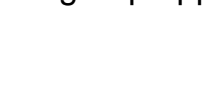 } & \multicolumn{2}{|l|}{ Enhanced } & \multicolumn{2}{|l|}{ Standard } \\
\hline & All periods & Last 5 periods & All periods & Last 5 periods \\
\hline Nash equilibrium & 300.0 & 300.0 & 180,0 & 180.0 \\
\hline Social optimum & 180.0 & 180.0 & 108.0 & 108,0 \\
\hline Baseline & $\begin{array}{l}296.5 \\
(8.62)\end{array}$ & $\begin{array}{l}298.0 \\
(9.98)\end{array}$ & $\begin{array}{l}192,4^{\cdots *} \\
(3,05)\end{array}$ & $\begin{array}{l}188.9 \\
(10.90)\end{array}$ \\
\hline Vote & $\begin{array}{l}292.6 \\
(5.06)\end{array}$ & $\begin{array}{l}298.9 \\
(3.93)\end{array}$ & $\begin{array}{l}226.1 \\
(32.96)\end{array}$ & $\begin{array}{l}\text { N/A } \\
\text { N/A }\end{array}$ \\
\hline PPM & $\begin{array}{l}272.1^{*} \\
(13,86)\end{array}$ & $\begin{array}{l}280.2^{*} \\
(10.74)\end{array}$ & $\begin{array}{l}196,7 \\
(9,50)\end{array}$ & $\begin{array}{l}182.6 \\
(27,69)\end{array}$ \\
\hline
\end{tabular}

Notes: Conditional group means are reported with clustered robust standard errors in parentheses; tests are for equality of observed and predicted appropriation, " $p<0.10 ; "{ }^{*} p<0,05 ;{ }^{* *} p<0.01$; in the last five periods, all groups in the vote treatment successfully enhanced the resource. 
arising in the standard baseline $(p<0.01)$ and in the enhanced PPM $(p=0.06)$. But even these two differences diminish or disappear in the final five periods. $\stackrel{8}{\text { Fig. } 3}$ illustrates these findings by showing appropriation as a percentage of the Nash prediction over the 20 periods-behavior is strikingly similar across treatments and closely corresponds to game-theoretic predictions.

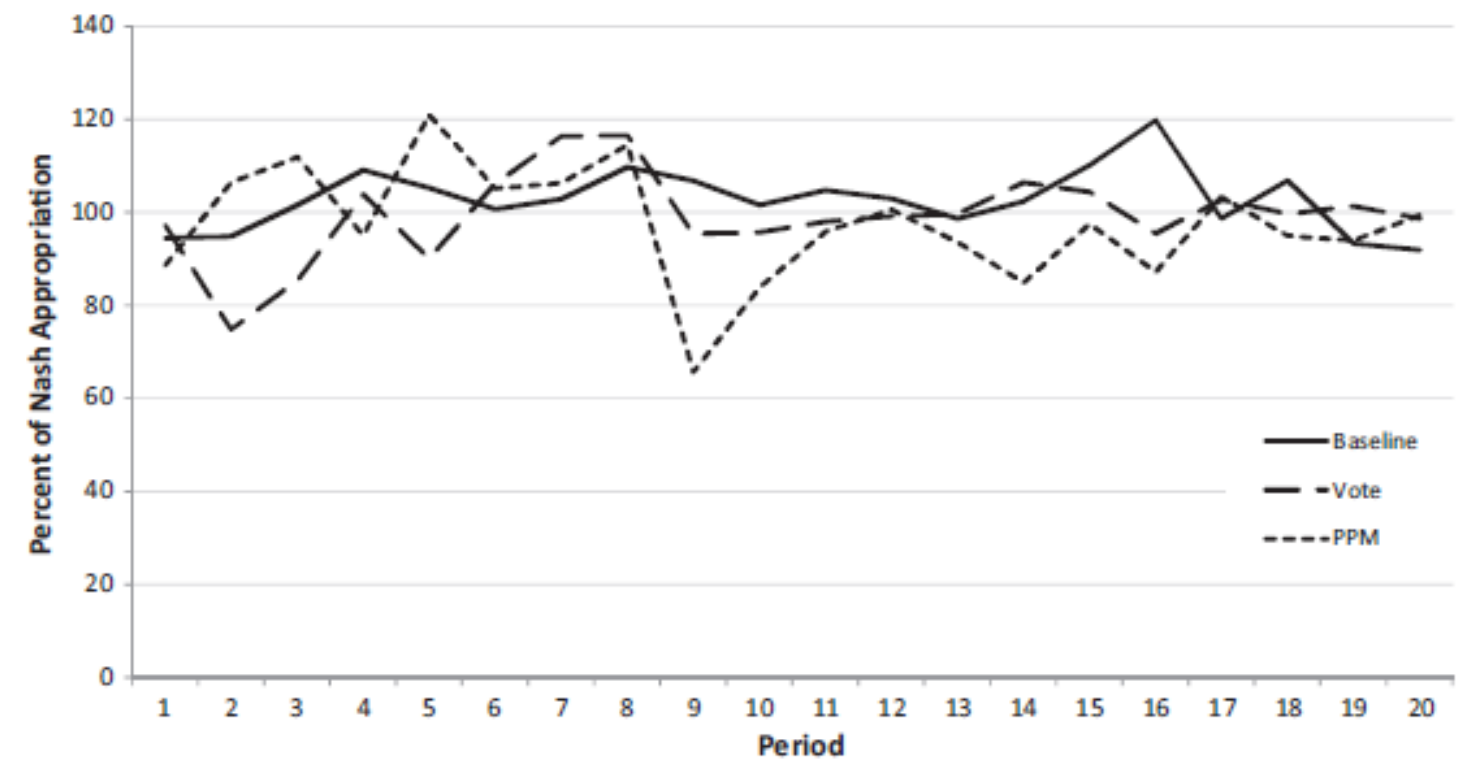

Fig. 3. Mean group appropriation as a percentage of Nash appropriation.

\subsection{Linking provision and appropriation}

We now consider how individual appropriation decisions might be influenced by the provision stage. In Table 4, we report the conditional means for individual appropriation across the person's provision decision and the group's success or failure to enhance the resource. The numbers reveal some patterns that are consistent with strategic reciprocity. In the voting treatment, when the resource is enhanced, group members that voted for enhancement in the provision stage appropriate at the Nash equilibrium level (59.9 vs. 60.0, $p=0.95)$. But when enhancement fails, the members that supported enhancement appropriate far more than predicted (54.6 vs. 36.0, $p=0.03$ ), despite the fact that higher levels of appropriation reduce their expected individual payoff as well as the group's payoff. This is consistent with cooperative members punishing the group (at a cost) for its failure to enhance 
Table 4. Mean individual appropriation by provision decision and outcome.

\begin{tabular}{|c|c|c|}
\hline & Enhanced & Standard \\
\hline Nash equilibrium & 60,0 & 36.0 \\
\hline Social optimum & 36,0 & 21.6 \\
\hline Baseline & $\begin{array}{l}59.3 \\
(1.71)\end{array}$ & $\begin{array}{l}38.5 \\
(0.60)\end{array}$ \\
\hline \multicolumn{3}{|l|}{ Vote } \\
\hline Supported (vote - yes) & $\begin{array}{l}59.9 \\
(1.40)\end{array}$ & $\begin{array}{l}54,6^{*} \\
(8,04)\end{array}$ \\
\hline Opposed (vote- no) & $\begin{array}{l}52,7^{\cdots *} \\
(2,40)\end{array}$ & $\begin{array}{l}39.6 \\
(5,74)\end{array}$ \\
\hline \multicolumn{3}{|l|}{ PPM } \\
\hline Supported $\left(c_{i} \geq 20\right)$ & $\begin{array}{l}52,0^{* *} \\
(3,05)\end{array}$ & $\begin{array}{l}39.4^{*} \\
(1.96)\end{array}$ \\
\hline Opposed $\left(c_{1}<20\right)$ & $\begin{array}{l}63.7 \\
(9.00)\end{array}$ & $\begin{array}{l}39.3 \\
(2,15)\end{array}$ \\
\hline Total & $\begin{array}{l}57.5 \\
(0.98)\end{array}$ & $\begin{array}{l}39.3 \\
(0.92)\end{array}$ \\
\hline
\end{tabular}

Notes: Conditional means are reported with cluster robust standard errors in parentheses; tests are for equality of observed and predicted mean appropriation, " $p<0.10$; " $p<0.05$; $\cdots " p<0.01$; support (opposed) indicates members voted "yes" ("no") in the vote treatment or contributed 20 or more (less than 20 ) in the PPM treatment.

Table 5. Random effects model of individual appropriation: between treatment behavior.

\begin{tabular}{llll} 
& Pooled & Enhanced & Standard \\
\hline Baseline & -2.54 & $-0,71$ & 2,48 \\
& $(3,61)$ & $(4,31)$ & $(5.26)$ \\
Vote & -0.01 & $-1,37$ & 8.92 \\
& $(2,94)$ & $(2,94)$ & $(6.55)$ \\
PPM & -4.45 & $-6,41^{* *}$ & 6.07 \\
& $(2.76)$ & $(3,07)$ & $(3.70)$ \\
$\chi^{2}$ & 66.59 & 40,27 & 26.80 \\
p-Value & $<0.001$ & 0.007 & 0.178 \\
$n$ & 1800 & 1240 & 560 \\
\# of clusters & 90 & 75 & 65 \\
\hline
\end{tabular}

Notes: Coefficients reported in the table are conditional mean deviations from Nash equilibrium predictions, Period effects are controlled for through period dummies (coefficients not reported); robust standard errors in parentheses; tests are for the null hypothesis that deviation from Nash is zero, " $p<0.10 ; " * p<0,05 ;{ }^{\cdots *} p<0,01$.

the resource-i.e., negative reciprocity. Turning to the PPM treatment, we see a different form of reciprocity. When the group fails to enhance the resource, the members that supported enhancement by contributing at cooperative levels $\left(c_{i} \geq 20\right)$ appropriate at levels marginally similar to the game-theoretic prediction (39.4 vs. 36.0, $p=0.10)$. But when the group successfully enhances the resource, members that cooperated in the provision stage $\left(c_{i} \geq 20\right)$ appropriate significantly less than predicted, even though the lower appropriation increases the group's payoff at the expense of their own (52.0 vs. $60, p=0.02) . \stackrel{10}{1}$ This is consistent with cooperative members rewarding the group (at a cost) for successfully enhancing the resource-i.e., positive reciprocity.

We also observe one other deviation from the game-theoretic prediction-when the group successfully enhanced the resource, the members that vote in opposition to 
enhancement appropriate significantly less than predicted (52.7 vs. $60.0 ; p=0.01$ ). This pattern is also consistent with reciprocal behavior-after learning their prior noncooperative behavior was in the minority, they signal cooperation by restraining appropriation to enhance the group's payoff at a cost to their own.

\subsection{Conditional analyses}

We follow these aggregate numbers with conditional analyses of individual appropriation behavior. For a between-treatment analysis we estimate the treatment effects on appropriation levels with the following model:

$$
a_{\text {it }}-a^{N E}=\beta^{\prime} \tau_{i}+\delta x_{i t}+\omega_{i}+\psi_{t}+\varepsilon_{i t}, \quad i=1,2, \ldots n ; \quad t=1,2, \ldots 20
$$

Table 6. Random effects model of individual appropriation: within treatment behavior.

\begin{tabular}{|c|c|c|c|}
\hline & Pooled & Vote & PPM \\
\hline Supported and enhanced & $\begin{array}{l}-1,68 \\
(3,11)\end{array}$ & $\begin{array}{l}-0.11 \\
(3.13)\end{array}$ & $\begin{array}{l}-9,76^{* *} \\
(3,08)\end{array}$ \\
\hline Opposed and enhanced & $\begin{array}{l}-0.51 \\
(3,83)\end{array}$ & $\begin{array}{l}-6.47^{* *} \\
(3.27)\end{array}$ & $\begin{array}{l}3.07 \\
(6.50)\end{array}$ \\
\hline Supported and standard & $\begin{array}{l}10.58^{* *} \\
(4,24)\end{array}$ & $\begin{array}{l}14.76^{\circ} \\
(8.88)\end{array}$ & $\begin{array}{l}5.33 \\
(3.30)\end{array}$ \\
\hline Opposed and standard & $\begin{array}{l}7.88 \\
(5,70)\end{array}$ & $\begin{array}{l}2,65 \\
(6,08)\end{array}$ & $\begin{array}{l}6,70 \\
(6,70)\end{array}$ \\
\hline $\begin{array}{l}\chi^{2} \\
p \text {-Value }\end{array}$ & $\begin{array}{l}83.58 \\
<0.001\end{array}$ & $\begin{array}{l}70.01 \\
<0.001\end{array}$ & $\begin{array}{l}299.62 \\
<0.001\end{array}$ \\
\hline$n$ & 1200 & 600 & 600 \\
\hline \# of clusters & 60 & 30 & 30 \\
\hline
\end{tabular}

Notes: Coefficients reported in the table are conditional mean deviations from Nash equilibrium predictions, Period effects are controlled for through period dummies (coefficients not reported); supported (opposed) indicates members voted "yes" ("no") in vote treatment or contributed 20 or more (less than 20) in the PPM treatment; enhanced (standard) indicates group success (failure) in enhancement; robust standard errors in parentheses; tests are for the null hypothesis that deviation from Nash is zero, $" p<0.10 ; " * p<0,05 ;{ }^{* *} p<0,01$.

where the dependent variable, $a_{i t}-a^{N E}$, denotes the difference between the ith subject's appropriation from the CPR in period $t$ and the Nash prediction; $\tau_{i}$ is a vector of indicator variables which specify the treatment for subject $i ; x_{i t}$ indicates whether the CPR is enhanced or not (=1 if enhanced; 0 otherwise); $\omega_{i}$ captures individual subject effects; $\psi_{t}$ captures period-specific effects; and $\varepsilon_{i t}$ represents the contemporaneous error term. $\underline{11}$ In addition to a pooled model, we estimate enhanced and standard models, which clarify any treatment effect specific to the provision mechanism.

$\underline{\text { Table } 5}$ presents estimated coefficients based on $\underline{(6)}$ for the pooled, enhanced and standard models. Results correspond to the two conclusions drawn from the aggregate data. First, the Nash solution concept performs well in organizing appropriation decisions, with observed behavior statistically matching game theoretic predictions in 
eight of the nine cases. The exception is a significantly lower level of appropriation in the PPM treatment, which is consistent with the finding reported in Table 3 of significantly lower than Nash group appropriation in the enhanced PPM. Second, the origin of the resource does not influence appropriation behavior. Appropriation is statistically equivalent whether the resource is exogenously or endogenously provided, and equivalent across the two endogenous provision mechanisms.

Turning to a within-treatment analysis, we explore behavioral linkages between the provision and appropriation of the resource by estimating the following model with data from the two provision treatments:

$$
a_{i t}-a^{N E}=\beta^{\prime} M_{i t}+\theta x_{P P M}+\omega_{i}+\psi_{t}+\varepsilon_{i t}
$$

where the dependent variable, $a_{i t}-a^{N E}$ difference between the ith subject's appropriation from the CPR in period $t$ and the Nash prediction; $M_{i t}$ is a vector of indicator variables indicating whether subject $i$ exhibited support for CPR enhancement in period $t$ ( $=1$ if true; 0 otherwise) and whether her group successfully enhanced the resource (=1 if "yes"; 0 otherwise) $\stackrel{12}{\text {; }} x_{P P M i}$ indicates whether the provision mechanism is a vote or PPM (=1 PPM; 0 otherwise); $\omega_{i}$ and $\psi_{t}$ capture subject- and period-specific effects; and $\varepsilon_{i t}$ represents the contemporaneous error term. We estimate a pooled model that includes data from both the voting and PPM treatments, and two treatmentspecific models that only include data from the voting or the PPM treatment.

From this specification, we obtain pooled and treatment-specific conditional estimates of how individual appropriation behavior deviates from theory in the four possible outcomes of the provision stage: (1) the individual supported enhancement of the resource and it was enhanced; (2) the individual opposed enhancement of the resource, but it was enhanced; (3) the individual supported enhancement of the resource, but enhancement failed; (4) the individual opposed enhancement of the resource and enhancement failed. Results are reported in Table 6. In eight of the twelve cases, tests fail to reject the null hypothesis that individual appropriation is the same as the Nash prediction, thereby providing additional empirical evidence for the Nash equilibrium concept. Of interest are the cases in which behavior significantly deviates from theory. In the vote treatment, when the group fails to enhance the resource, the members that supported enhancement appropriate marginally significantly more than predicted $(p=0.10)$, although not significantly more than their non-cooperative counterparts $(p=0.21)$. In the PPM treatment, when the resource is successfully enhanced, the members that cooperated $\left(c_{i} \geq 20\right)$ appropriate significantly less than predicted $(p<0.01)$ and significantly less than their non-cooperative counterparts $(p=0.06)$. Also in the PPM treatment, estimates indicate the members that chose not to cooperate in a 
successful provision of the resource appropriate significantly less than predicted. The results therefore corroborate the finding that individual behavior is consistent with reciprocal behavior, and in particular, consistent with efforts to facilitate cooperation in resource enhancement with negative reciprocity in the voting treatment (i.e., a stick) and positive reciprocity in the PPM treatment (i.e., a carrot).

We extend the analysis to investigate possible dynamic effects-i.e., whether behavior in one period is significantly influenced by behavior in prior periods. We test for three potential sources of dynamic effects: the influence of prior provision decisions on current provision decisions, the influence of prior appropriation decisions on current provision decisions, and the influence of prior appropriation decisions on current appropriation decisions. In each case, we find no evidence of dynamic effects. $\stackrel{13}{\text { We do }}$ find that a member's past appropriation behavior is a reasonable predictor of her current appropriation behavior, but prior group outcomes do not explain current appropriation behavior.

\section{Conclusion}

The extensive experimental literature on social dilemmas has greatly enhanced our understanding of how behavioral and institutional elements affect cooperative solutions to collective-action problems. Existing research focuses on either the public good game or the common-pool resource game, but there are many settings that are best characterized by considering these two games jointly. Herein we construct a dual social dilemma in which the potential benefits of a common-pool resource are endogenously determined by the voting decisions or voluntary contributions of group members to develop the resource. This framework allows an examination of two lines of inquiry in the literature. First, we examine whether appropriation behavior is affected by the origin of the common-pool resource, and second, we examine whether people identify and utilize opportunities for strategic reciprocity to facilitate cooperative behavior.

Results show the Nash solution concept is a powerful predictor of behavior in our dual social dilemma setting. The observed levels of appropriation are remarkably consistent with game-theoretic predictions whether the resource was endogenously or exogenously determined and whether the resource was enhanced or not. This result stands in contrast to other studies that have found the origin of resources can influence behavior in a public good game (e.g., Harrison, 2007 and Kroll et al., 2007). The finding that the origin of the common-pool resource did not affect appropriation behavior provides additional confidence in the generalizability of previous experimental studies that employ exogenously provided resources. 
This result however comes with a caveat. While endogenously determining the resource did not significantly affect group appropriation levels, it did lead to significant differences in individual behavior that are consistent with strategic reciprocity. In particular, when the resource was provided through a voting mechanism, users appear to punish the group for failed resource enhancement by being less cooperative in appropriation, but when the resource was provided via a provision-point mechanism, users appear to reward the group for successful resource enhancement by being more cooperative in appropriation. The dual social dilemma opened channels for strategic reciprocity, and our results suggest that group members identified and utilized these channels. Thus, endogenous provision appears to have affected individual behavior, but in our settings, these influences did not translate to impacts on overall appropriation. Changes to the setting, such as the parameters or provision mechanism, could affect individual behavior in ways that lead to an impact on overall appropriation. Considering the relevance of endogenously determined resources, future efforts should further explore how provision affects the use of common-pool resources. 


\section{References}

Andreoni, J., Harbaugh, W., Vesterlund, L., 2003. The carrot or the stick: rewards, punishments, and cooperation. The American Economic Review 93 (3), 893-902.

Arkes, H., Joyner, C., Pezzo, M., Nash, J., Siegel-Jacobs, K., Stone, E., 1995. The psychology of windfall gains. Organizational Behavior and Human Decision Processes 59 (3), 331-347.

Bagnoli, M., McKee, M., 1991. Voluntary contribution games: efficient private provision of public goods. Economic Inquiry 29 (2), 351-366.

Baland, J.-M., Platteau, J.-P., 1996. Halting Degradation of Natural Resources: Is There a Role for Rural Communities? Oxford University Press, New York/Oxford.

Bischoff, I., 2007. Institutional choice versus communication in social dilemmas-an experimental approach. Journal of Economic Behavior \& Organization 62 (1), 20-36.

Budescu, D., Rapoport, A., Suleiman, R., 1995. Common pool resource dilemmas under uncertainty: qualitative tests of equilibrium solutions. Games and Economic Behavior 10, 171-201.

Cadsby, C.B., Maynes, E., 1999. Voluntary provision of threshold public goods with continuous contributions: experimental evidence. Journal of Public Economics 71 (1), 53-73.

Cardenas, J., 2011. Social norms and behavior in the local commons as seen through the lens of field experiments. Environmental and Resource Economics 48 (3), 451-485.

Cherry, T., Frykblom, P., Shogren, J., 2002. Hardnose the dictator. The American Economic Review 92 (4), 1218-1221.

Croson, R., Marks, M., 2000. Step returns in threshold public goods: a meta- and experimental analysis. Experimental Economics 2, 239-259.

Fehr, E., Gächter, S., 2000. Cooperation and punishment in public goods experiments. The American Economic Review 90 (4), 980-994. 
Fischbacher, U., 2007. Z-tree: Zurich toolbox for ready-made economic experiments. Experimental Economics 10 (2), 171-178.Hardin, G., 1968. The tragedy of the commons. Science 162 (3859), 1243-1248.

Harrison, G., 2007. House money effects in public good experiments: comment. Experimental Economics 10 (4), 429-437.

Isaac, R., Walker, J., 1998. Nash as an organizing principle in the voluntary provision of public goods: experimental evidence. Experimental Economics 1 (3), 191-206.

Janssen, M., Anderies, J., Joshi, S., 2011. Coordination and cooperation in asymmetric commons dilemmas. Experimental Economics 14 (4), 547-566.

Kroll, S., Cherry, T., Shogren, J., 2007. The impact of endowment heterogeneity and origin on contributions in best-shot public good games. Experimental Economics 10 (4), 411-428.

Lam, W.F., 1998. Governing Irrigation Systems in Nepal: Institutions, Infrastructure and Collective Action. ICS Press, Oakland.

Meinzen-Dick, R., Raju, K., Gulati, A., 2002. What affects organization and collective action for managing resources? Evidence from Canal Irrigation systems in India. World Development 30 (4), 649-666.

Ostrom, E., 1996. Incentives, rules of the game, and development. In: Proceedings of the annual World Bank conference on development economics, 1995, pp. 207-234.

Ostrom, E., 2000. Collective action and the evolution of social norms. Journal of Economic Perspectives 14 (3), 137-158.

Ostrom, E., 2006. The value-added of laboratory experiments for the study of institutions and common-pool resources. Journal of Economic Behavior \& Organization 61 (2), 149-163.

Ostrom, E., Gardner, R., Walker, J., 1994. Rules, Games, and Common-pool Resources. University of Michigan Press, Ann Arbor.

Rodriguez-Sickert, C., Guzmán, R.A., Cárdenas, J.C., 2008. Institutions influence preferences: evidence from a common pool resource experiment. Journal of Economic Behavior \& Organization 67 (1), 215-227. 
Samuelson, P.A., 1954. The pure theory of public expenditure. The Review of Economics and Statistics 36 (4), 387-389.

Schnier, K., 2009. Spatial externalities and the common pool resource mechanism. Journal of Economic Behavior and Organization. 70 (1-2), 402-415.

Sefton, M., Shupp, R., Walker, J.M., 2007. The effect of rewards and sanctions in provision of public goods. Economic Inquiry 45 (4), 671-690.

Sserunkuuma, D., Ochom, N., Ainembabazi, H., 2008. Collective Action in Canal Irrigation Systems Management: The case of Doho Rice Scheme in Uganda. International Food Policy Research Institute (IFPRI) http://hdl.handle.net/1902.1/11313

Thaler, R., 1985. Mental accounting and consumer choice. Marketing Science 4 (3), 199-214.

Varughese, G., 1999. Villagers, Bureaucrats, and Forests in Nepal: Designing Governance for a Complex Resource. Dissertation. Indiana University, Bloomington, IN.

Vyrastekova, J., van Soest, D., 2003. Centralized common-pool management and local community participation. Land Economics 79 (4), 500-514.

Walker, J.M., Gardner, R., Ostrom, E., 1990. Rent dissipation in a limited-access common-pool resource: experimental evidence. Journal of Environmental Economics and Management 19 (3), 203-211.

Walker, J.M., Gardner, R., Herr, A., Ostrom, E., 2000. Collective choice in the commons: experimental results on proposed allocation rules and votes. Economic Journal 110, 212-234.

West, C., 2010. Household extension and fragmentation: investigating the socioenviromental dynamics of mossi domestic transitions. Human Ecology 38 (3), 363-376. 